\title{
BIOMASS UTILIZATION AS A RENEVABLE ENERGY SOURCE IN POLISH POWER INDUSTRY - CURRENT STATUS AND PERSPECTIVES
}

\author{
Beata Gołuchowska', Jarosław Sławiński', Grzegorz Markowski \\ 1 Department of Land Protection, Faculty of Nature and Technology, Opole University, Oleska 22, 45-052 Opole, \\ Poland, e-mail: beska@uni.opole.pl; jarek19@uni.opole.pl \\ 2 ATMOTERM S.A., Łangowskiego 4, 45-031 Opole, Poland, e-mail: marmo_s@o2.pl
}

Received: 2015.05 .14

Accepted: 2015.06.02

Published: 2015.07.01

\begin{abstract}
The depletion of the conventional energy sources, as well as the degradation and pollution of the environment by the exploitation of fossil fuels caused the development of renewable energy sources (RES), including biomass. In Poland, biomass is the most popular renewable energy source, which is closely related to the obligations associated with the membership in the EU. Biomass is the oldest renewable energy source, and its potential, diversity and polymorphism place it over other sources. Besides, the improvement in its parameters, including an increase in its calorific value, resulted in increasing use of biomass as energy source. In the electric power industry biomass is applied in the process of co-combustion with coal. This process may contribute, inter alia, to the reduction in the emissions of carbon, nitrogen and sulfur oxides. The article presents the characteristics of the biomass burned in power boilers of one of the largest Polish power plants, located in Opole Province (Southern Poland). Besides, the impact of biomass on the installation of co-combustion, as well as the advantages and disadvantages of the co-combustion process not only in technological, but also environmental, economic and social aspects were described.
\end{abstract}

Keywords: biomass, co-combustion, power plant, renewable energy sources.

\section{INTRODUCTION}

Currently, like in previous years, the main sources of energy for the industry and municipal management are fossil fuels such as hard coal, lignite, crude oil and natural gas. Non-renewable resources of these fuels decrease, what may result in a lack of energy supply. Their exploitation conflicts with the principle of sustainable development and can lead to irreversible geomorphological changes in the environment. The common use of fossil fuels also involves significant dust and gas emissions, including sulfur, nitrogen and carbon oxides, which is considered the main cause of the so-called global warming and acid rain. Therefore, the efforts are made on a large scale aimed at obtaining energy from renewable resources, which include: biomass, hydropower, wind energy, geothermal resources and solar energy.

Biomass is a precursor and the oldest renewable energy source. It has the widest possibilities of application compared with other RES, because it includes, inter alia, organic waste from agriculture, forestry, as well as various industries and municipal management. Versatility of biomass also follows from the fact, that it occurs in the three states of matter: solid, liquid and gaseous. In Polish conditions, biomass is the best renewable energy source because of its rich reserves, many possibilities of application and favorable climatic and geographical conditions for its production. The share of agricultural land in the area of the country is one of the largest in Europe $(61 \%)$, and they have a larger area (15.6 million hectares), than in other Central European countries. Technical potential of biomass in Poland is estimated at approximately $900 \cdot 10^{15} \mathrm{~J}$ per year [Bartosiewicz-Burczy 2012]. Biomass used in Polish power industry is almost entirely produced in the country, and Poland is one of the largest exporters of biomass in Europe. As regards to the other RES, there are significant limitations of the 
use of wind energy (small resources and unfavorable topography), as well as water power (low resources). Geothermal energy, by contrast, is much less available and favorable conditions for its use occur only in a few places in the country. In case of solar power, the limiting factor is the high price of photovoltaic cells.

RES development has become one of the main objectives of the European Union. During the meeting of the European Council in 2007, all countries adopted the so-called $3 \times 20$ package, which assumes - up to the year 2020 - the reduction in greenhouse gas emissions by $20 \%$, increase in energy efficiency by $20 \%$ and rise in the share of RES in the total energy production to the level of 20\% [Karpińska, Dul 2014].

This article evaluates the process of biomass co-combustion with hard coal in one of the largest Polish power plants, located in Opole Province (Southern Poland). The following problems were presented: advantages and disadvantages of biomass application in the co-combustiong process, taking into account environmental, economic, technological and social aspect, the current status of biomass in Polish energy market, its application in power industry, and the prospects. The article is based on the information obtained in the above-mentioned power plant and literature data.

\section{CHARACTERISTICS OF THE OBJECT OF RESEARCH}

The object of the study was the electric power plant with total installed capacity of $1492 \mathrm{MW}$, located near the city of Opole. The plant has been operating since 1994 and is now the most modern coal-fired power plant in Poland, and the leader of the Polish energy market in terms of quantity of consumed biomass. The power plant burns 150 thousand $\mathrm{Mg}$ of biomass per year, which is a larger amount than in the case of other Polish power plants, even those about the greater power, like Bełchatów (5354 MW of installed capacity, 136 thousand $\mathrm{Mg}$ of biomass consumed per year), and Turów (1900 MW of installed capacity, 144 thousand $\mathrm{Mg}$ of biomass consumed per year) [Frączkowski 2011]. The power plant is one of the precursors of the process of biomass cocombustion with hard coal in Poland. In the year $2010,1.9 \%$ of the total amount of energy came from biomass. The concession for the combustion of biomass in the context of its co-combustion with hard coal and the production of electricity classified as coming from RES, the described power plant obtained in 2004. Two years later the concession was extended for the production of electricity from biomass of the plant origin, derived from agriculture by-products and residues, as well as the industry which processes these products.

Biomass is acquired by way of tenders and delivered to the plant by road transport. Then, the fuel is carried by conveyor system to coal mills, where the mixture of coal dust and biomass is ground into fine dust. The dust is transported pneumatically through dust ducts to the furnace chamber of steam boiler, where it undergoes complete burning giving off heat through screens, steam heaters and water heater. After discharging from the boiler, the hot flue gas also gives the heat back in rotary air heaters and is purified off fly ash in electrofilters (ESPs). Next, the flue gas enters the installation of desulphurization, from where it is transported to the chimney. During the launch of power blocks as well as to stabilize the combustion process in operational disruptions, the installation of fuel oil is used. The produced superheated steam drives a steam turbine, which is directly coupled to a generator. After working on the rotor of the turbine, the steam is condensed in the condenser, and the heat released during condensation is dissipated by the cooling water in the cooling tower to the atmosphere. The condensed water from the condenser is pumped through the regenerative heat exchangers. After heated in the low and high pressure regeneration, water again is forced under high pressure (approx. 200 bar) into the boiler. Electric energy produced in the generator is output through the power lines to the National Energy System. For technological purposes water is collected from the intake on the Mała Panew river (Opole Province). Collected water is chemically treated so that it can meet the high technological requirements of the cooling system and the steam-water system.

In the light of Polish legislation, biomass burned at the described power plant has not the status of waste but a renewable fuel. Waste burning at this plant is not conducted due to technical and economic reasons, resulting from the limitations in the use of waste in Polish power industry, as defined in the Regulation of the Minister of the Environment of 4 November 2014 on emission standards for some kinds of installations, sources of fuel combustion and devices of waste combus- 
tion or co-combustion [Journal of Laws of 2014, item 1546].

Fly ash - a by-product of co-combustion in the tested power plant, is a valuable raw material for the production of building materials - concrete and cement, and is also exported abroad. In previous years, a small amount of combustion waste - fly ash and slag - was used to reclamation of quarries after marl exploitation in Opole Province (filling in a form of emulgate) and restoration of land degraded by mining.

In 2012 the plant received funding from the European Fund of Regional Development for the construction of installation for direct supply of biomass (direct co-combustion) to the boiler No. 2 with a capacity of $100 \mathrm{MW}$. The most important purpose of the construction of this installation was environmental effect, achieved by the reduction in carbon dioxide emission into the atmosphere by $129600 \mathrm{Mg}$ per year. During the construction of this installation in the combustion chamber of the boiler special biomass burners will be installed so that fuel supply to the boiler will not be carried out by the coal mills. This allows for better conditions for fuel preparation before its delivery to the combustion chamber and more efficient combustion of biomass with coal dust.

\section{FUELS APPLIED IN THE CO-COMBUSTION PROCESS}

The tested power plant applies hard coal together with biomass. Besides, heavy fuel oil (tar) also participates in the process of co-combustion

\section{Hard coal}

Hard coal burned in the tested power plant came from three sources: Coal Company Inc. (60\% of supplies), Katowicki Coal Holding Inc. (40\%) and Jastrzębska Coal Company Inc. (40\%). The sulfur content in this fuel varied in the range of $0.70 \%$ to $0.85 \%$, and in the years $2009-2011$ was less than $0.80 \%$. The content of elemental carbon, which reflects the calorific value of the fuel (the more elemental carbon in the fuel, the greater its calorific value), varied in the range of $56 \%$ to $58 \%$. Fuel moisture was quite variable and ranged from $8.44 \%$ to $9.64 \%$. However, a slight tendency towards increasing moisture can be observed (Figure 1)

The best parameters characterized the coal burned in 2009, since sulfur and moisture content was the lowest, meaning low energy consumption required to evaporate the water contained in the coal. Besides, the reduction in sulfur content in the combusted coal is advantageous due to the reduction in the emissions of sulfur compounds to the ambient air.

According to the data presented in Figure 2, the largest amount of hard coal was burned in the year 2007 (over $3.5 \cdot 10^{6} \mathrm{Mg}$ ). In the following years, the amount of this fuel ranged from 3.2 to $3.4 \cdot 10^{6} \mathrm{Mg}$, while the least amount of hard coal was burned in 2010 .

\section{Biomass}

Biomass as an energy carrier differs from hard coal in terms of physical and chemical properties (Figures 3-5), and their comparison allows to de-

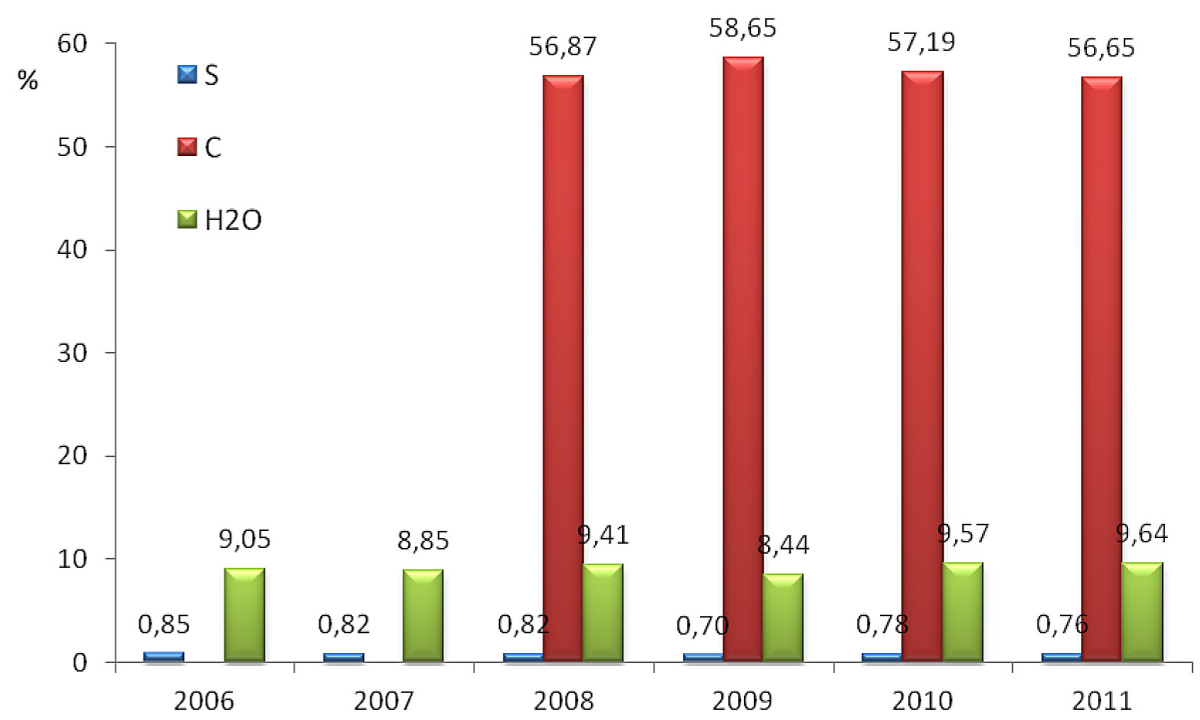

Figure 1. The percentage of sulphur $(\mathrm{S})$, carbon $(\mathrm{C})$ and moisture $\left(\mathrm{H}_{2} \mathrm{O}\right)$ in hard coal combusted in the described power plant in the years 2006-2011 (source: own elaboration based on data from Opole Power Plant) 


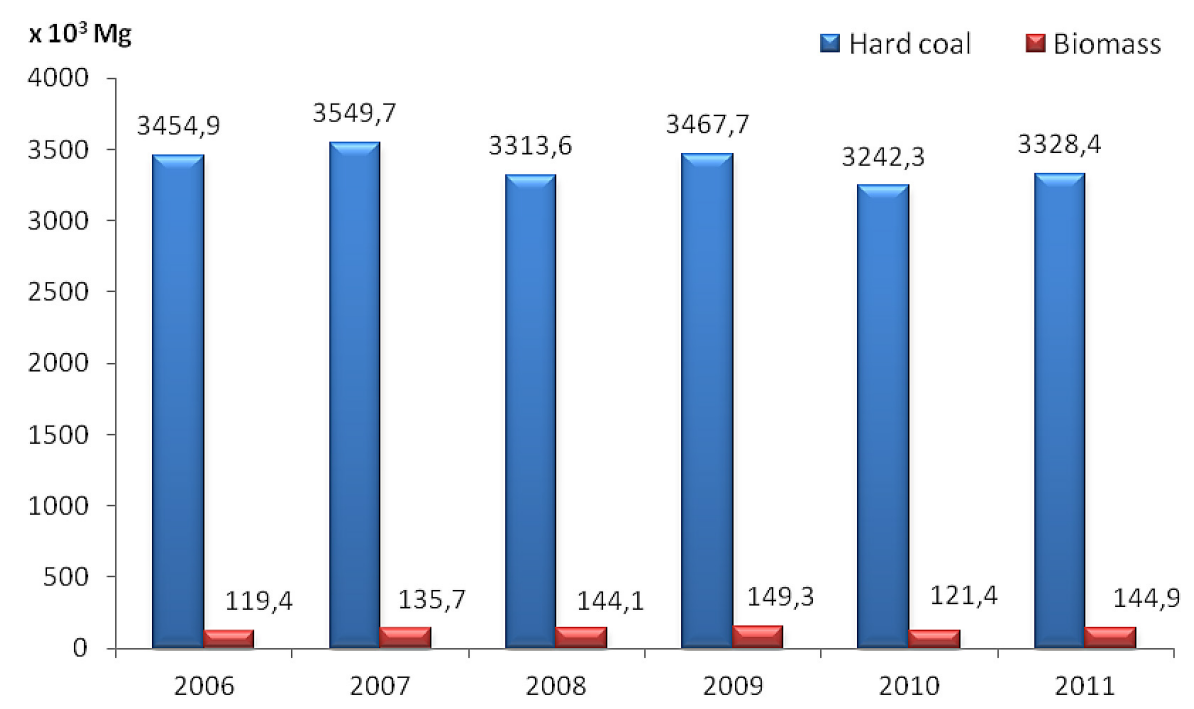

Figure 2. The comparison of the quantities of hard coal and biomass utilized in the described power plant in the years 2006-2011 (source: own elaboration based on data from Opole Power Plant)

termine the advantages and disadvantages of biomass as a fuel. The moisture content in biomass is highly diversified, e.g. freshly cut wood contains about $50 \%$ water, but after one year of seasoning, i.e. natural drying, the water content in the wood decreases to 25-30\% [Kozłowski, Cygan 2011]. The calorific value of wood and other kinds of biomass is lower than the conventional fuel, mainly due to the high moisture content, which - in the case of raw biomass - is in the range of $45-60 \%$, depending on the time of collection, and negatively affects the efficiency of the combustion process. Low calorific value per volume unit necessitates the application of several times larger biomass volumes in order to provide the same amount of energy to the process, compared with hard coal.

In order to adapt to the construction requirements of internal combustion engines (ICE), the biomass requires processing, like crude oil and natural gas. Unprocessed biomass is only the raw material and it is not a valuable fuel until its treatment. The processing of biomass aims at modification of its unfavorable properties, especially reduction in moisture content and increase in the amount of energy per unit volume, which particularly relates to timber. In addition, as a result of processing, the biomass obtains the form which facilitates boiler automation. The cheapest methods of biomass processing include: pressing, chipping, briquetting and pelleting [Juliszewski 2009].

An important parameter characterizing the fuel from the point of view of its energy usefulness is the content of volatile compounds, which in the biomass is $2-3$ times higher than in the hard coal. The fuels containing high amount of vola- tiles generate a long flame during combustion and require supplying an additional quantity of air for a complete, smokeless combustion. The high content of volatile compounds changes dynamic and thermal conditions of the combustion process, which makes the "clean combustion" of biomass in a typical coal-fired boiler impossible. For this reason, the biomass mixed with coal is burnt in power plants, or new boilers intended only for biomass combustion are built [Skrobacka 2007].

Biomass contains less ash than coal, but lower combustion temperature of the mixture of coal and biomass may result in the formation of larger amount of slag and impurities, which depends on the chemical and mineralogical properties of the mixture [Munir at al. 2011].

Comparing the chemical composition of ash after hard coal combustion and biomass (Figure 5), the ash from biomass is poorer in iron and silicon, and also contains a much smaller amount of sodium and sulfur, which is important from the point of view of environment protection. In turn, potassium, manganese and barium, are present in the ash from biomass in much larger quantities than in the ash from hard coal. The high content of iron, silicon, and especially potassium in the ash from biomass is a negative occurrence, since it can have a negative impact on the process of slagging, worsen the work of boilers, as well as cause the process of agglomeration. To prevent or reduce the occurrence of these unwanted phenomena, the content of potassium in combusted biomass should be as low as possible. According to the data shown in the Figure 5, the best solution would be co-combustion of forest biomass. 


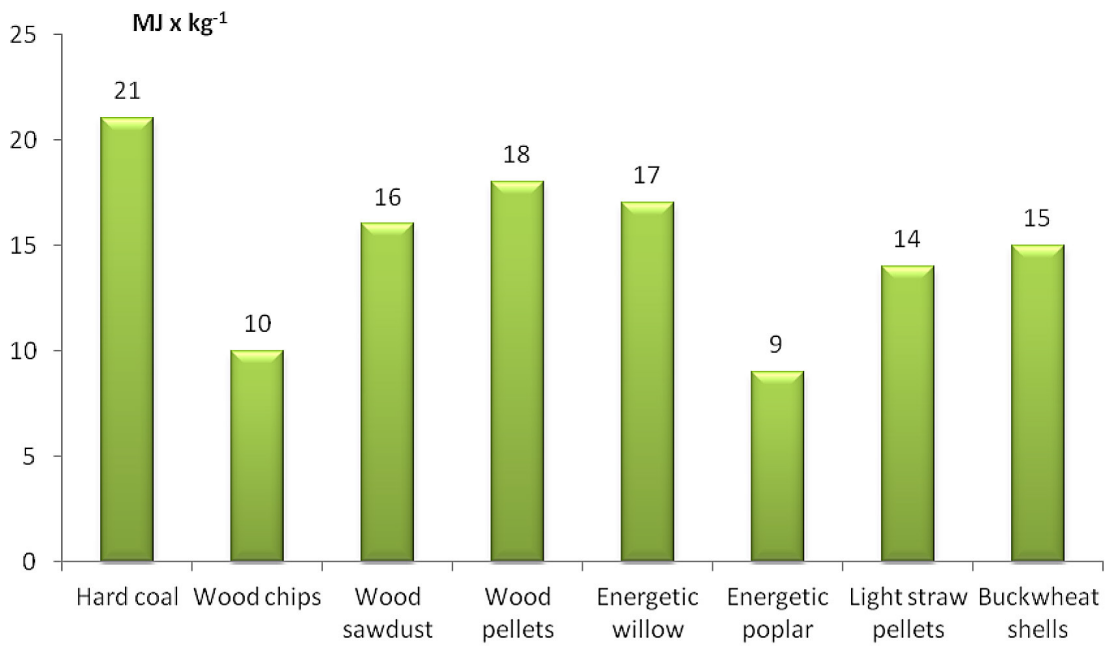

Figure 3. The comparison of calorific value of hard coal and chosen kinds of biomass (source: own elaboration based on data from R. Szymanowicz 2012)

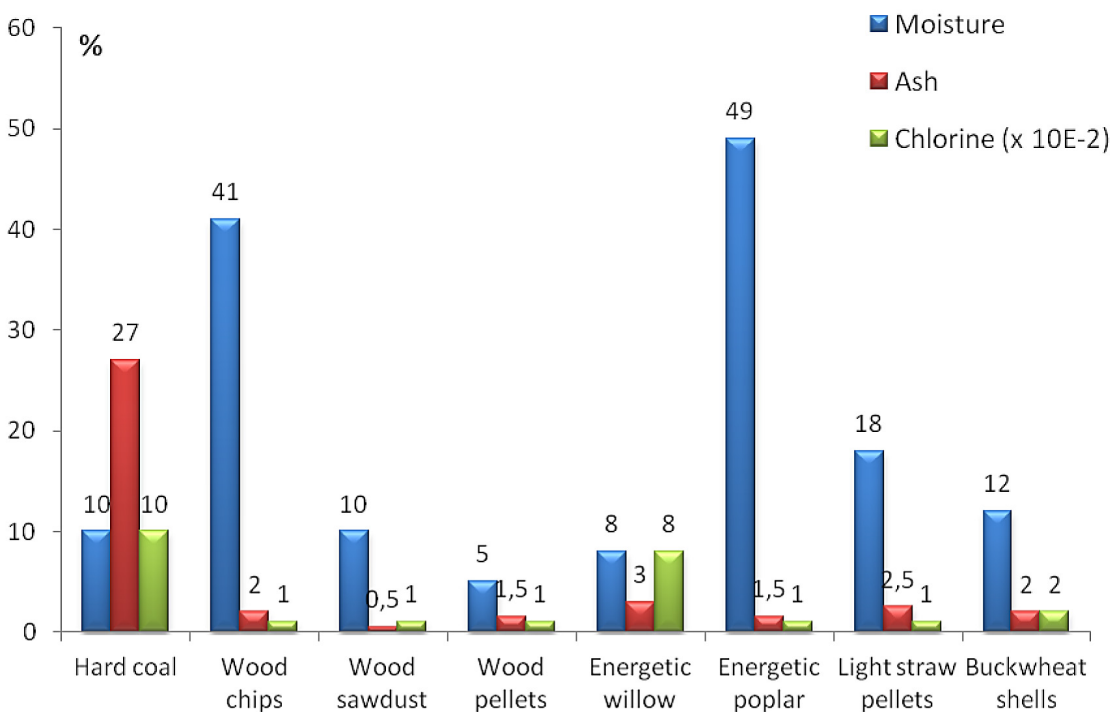

Figure 4. Percentage of ash, moisture $\left(\mathrm{H}_{2} \mathrm{O}\right)$ and chlorine $(\mathrm{Cl})$ an hard coal and chosen kinds of biomass (source: own elaboration based on data from R. Szymanowicz 2012)

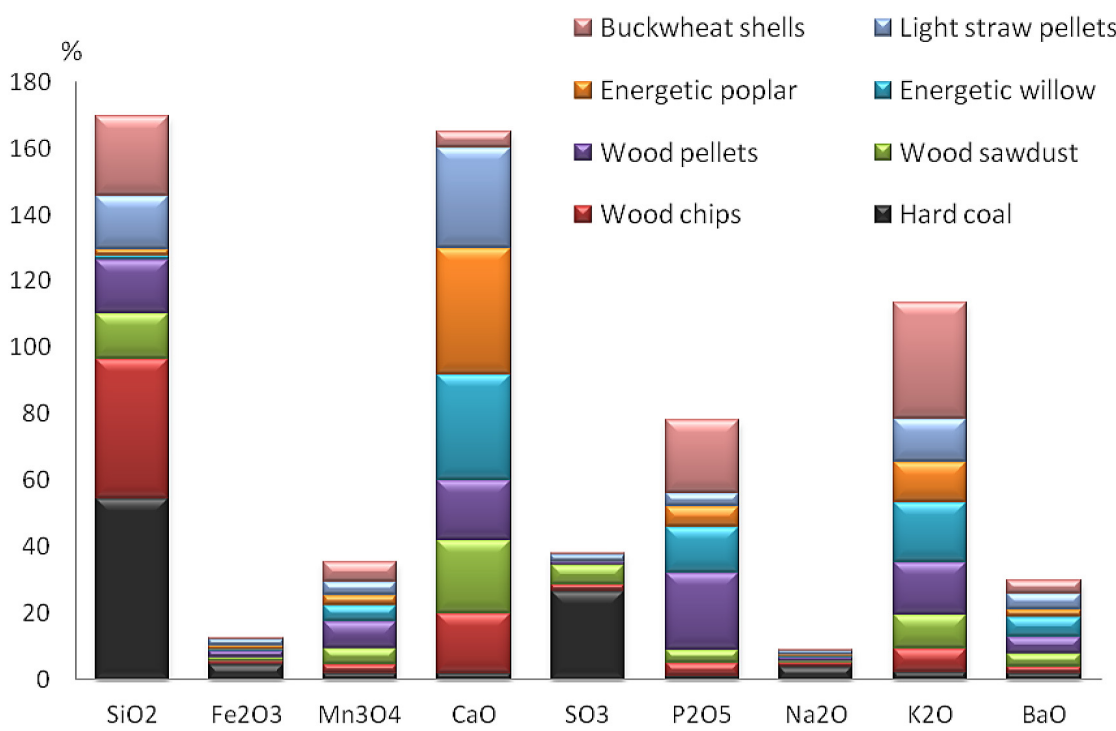

Figure 5. Chemical composition of ash from hard coal and biomass combustion (source: own elaboration based on data from R. Szymanowicz 2012) 
According to the data obtained in the described power plant, the content of elemental carbon in the biomass is generally twice lower than in the hard coal. Biomass burned in the power plant in the years 2008-2010 contained approx. 33\% of this element (Figure 6). In the year 2011, the content of carbon in biomass increased to about $36 \%$, which accounted for more than half of the content of this element in the co-combusted coal. This proves good calorific value of the biomass applied in this period of time. The biomass applied in 2006 was characterized by high water content (over 40\%), and in the following years the moisture content of biomass decreased, reaching the lowest value in the year 2009 (33\%). In 2011, the content of moisture in biomass increased again to a value of 35\%. The biomass applied in 2009 had the most favorable chemical composition due to the optimal content of elemental carbon and the lowest moisture content, which was associated with a reduction in energy consumption for water evaporation.

The power plant currently burns two kinds of biomass, originated from forests and agricultural activities. The forest biomass is: sawdust with calorific value of $7-15 \mathrm{GJ} / \mathrm{Mg}$, wood chips with a maximum diameter of $25 \mathrm{~mm}$ and the calorific value of 7-15 GJ/Mg, and shredded tree bark ground to a granulation of $25 \mathrm{~mm}$, with a calorific value of $7-15 \mathrm{GJ} / \mathrm{Mg}$. Biomass of agricultural origin, which has a lower moisture content than the forest biomass, was made up of chips of energetic willow (Salix viminalis) or other energetic plants such as: poplar (Populus), Jerusalem artichokes (Helianthus tuberosus) and rose, with a calorific value of $6-15 \mathrm{GJ} / \mathrm{Mg}$, as well as pellets obtained from straw, grass and other raw materials of agricultural origin - bran, chaff, husk etc., with a calorific value of $14-18 \mathrm{GJ} / \mathrm{Mg}$.

Both kinds of biomass are prepared outside the power plant, and their mass fraction in the overall balance of fuel does not exceed $8 \%$. However, tests carried out at the power plant have shown, that it can consume more amount of biomass in the overall balance of fuel - from 5 to $10 \%$. The power plant currently burns about $150 \cdot 10^{3} \mathrm{Mg}$ of biomass per year (Figure 2), but thanks to the new installation for direct combustion, a twofold increase in the amount of combusted biomass (to the level of the about $300 \cdot 10^{3} \mathrm{Mg}$ ) is planned, which is consistent with the objectives of the Polish energy policy until the year 2030. The least amount of biomass was burned in $2006\left(119 \cdot 10^{3}\right.$ $\mathrm{Mg}$ ), when the process of co-combustion started. After the completion of the project of biomass direct administration, further development of cocombustion installation is planned.

\section{THE EVALUATION OF THE PROCESS OF BIOMASS CO-COMBUSTION IN POWER INDUSTRY}

\section{Environmental protection aspects}

Research has shown that emission indicators of various pollutants into the atmosphere from the process of biomass co-combustion are not lower, compared with hard coal [Wielgosinski 2009]. This concerns particularly organic compounds, whose emissions from the energetic combustion of non-waste fuels, including biomass, in Poland

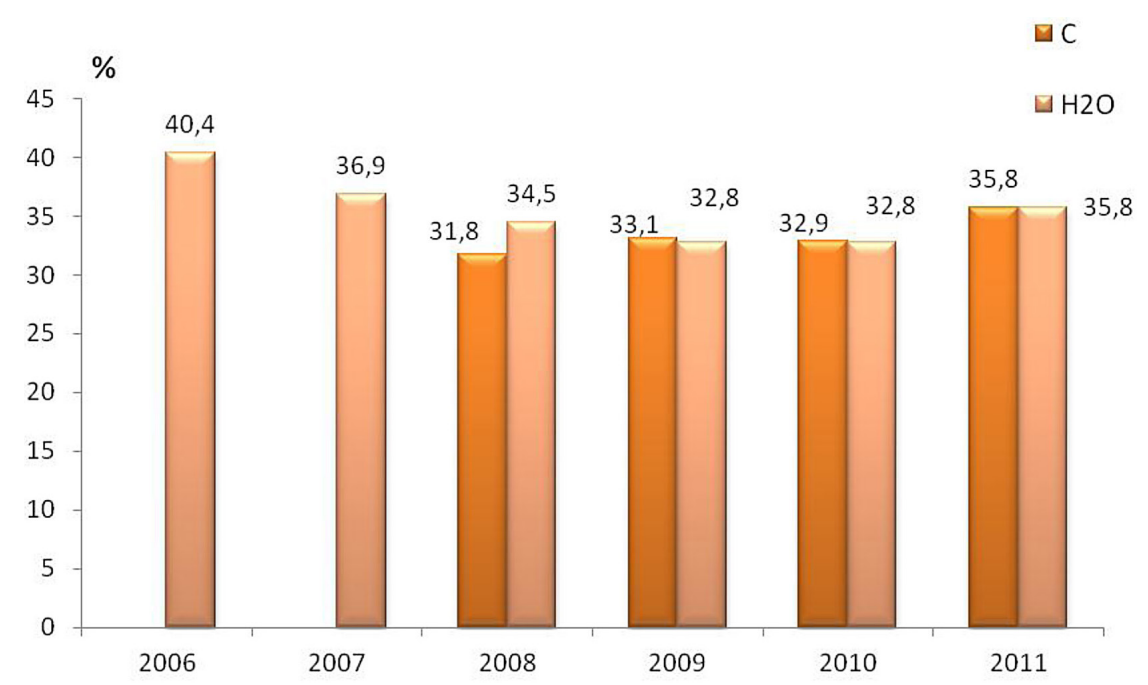

Figure 6. The percentage of carbon $(\mathrm{C})$ and moisture $\left(\mathrm{H}_{2} \mathrm{O}\right)$ in the biomass utilized in the described power plant in the years 2006-2011 (source: own elaboration based on data from Opole Power Plant) 
is not standardized [Dz.U. 2014, poz. 1546]. In this respect, biomass combustion may pose a threat to the environment and be a source of uncontrolled emissions of such pollutants as dioxins and furans.

From the point of view of environment protection, the combustion of forest biomass is a highly controversial issue. Opponents of deforestation for energy production rely on the beneficial functions of forests in ecosystem, including the production of oxygen in photosynthesis. In addition, the renewal of forest resources is a very slow process. Low availability of wood and high demand for this product is the reason for a steady increase in prices and search for cheap sources of wood by power plants. This can lead to burning imported raw material from illegal logging of trees, including the rainforests, responsible for the Earth's climate. On the other hand, the foresters believe that the combustion of forest biomass is beneficial, because rapid decaying of thin branches and needles - the most valuable part of the biomass - is mostly used for energy purposes. Moreover, the logging of trees helps control pine weevil (Hylobius abietis), one of the pine pests by limiting its food base, as well as facilitates further activities related to the renewal and care of the forest [Świstak 2008].

The most favorable is acquisition of biomass from home region, since its transport over long distances is associated with emissions from vehicles, by which it is transported. The interest in establishing plantations of biomass plants decreased among Polish farmers, because the government abolished subsidies for energy crops. This may contribute to the growth of import of biomass [Jabłoński 2008].

Biomass can be supplied to the power plant by water, road and rail transport. Each power plant has a close network with railway and road freight traffic, by which the primary fuel (coal) is provided, and also - due to technological reasons power plants are located near watercourses, which enables water transport of fuel. This range of options allows for the selection of environmentally friendly way of biomass transport and react to the changes in prices of transport [Wiśniewski 2011].

By-product of biomass co-combustion ash - is a highly sought-after raw material on the market, which gives great possibilities of its disposal. Ashes from the co-combustion of coal with biomass and the biomass itself are used in architecture and agriculture. Extensive research on the use of fly ashes in agriculture has shown, that their introduction into the soil contributes to the improvement of its water properties, soil compaction, reduces losses of fertilizers due to leaching, neutralizes soil acidity, enriches the soil with alkaline cations (calcium and magnesium), and contributes to the sanitation of contaminated soils [Myszkowska et al. 2011, Rosik-Dulewska 2009, 2012, Rosik-Dulewska et al. 2008]. The use of fly ashes originated from the co-combustion process in architecture is possible if they meet the requirements that ensure the technical quality of products obtained with their participation, and do not deteriorate their properties from environmental protection point of view. Particular attention is paid to the leachability of hazardous constituents from ashes (including heavy metals and organic compounds), the forms of their occurrence (determined by chemical sequential extraction methods), and the level of radioactivity [Rosik-Dulewska 2009, 2012, Rosik-Dulewska et al. 2008].

The process of biomass co-combusion in power industry, starting in Poland on a large scale, launches a search for solutions of ash management, e.g. for fertilization of energetic plants. The barrier to obtain appropriate permits is the need for constant and reproducible chemical composition of the product, which is difficult in the case of ashes from co-combustion. In addition, the physical form of ash is disadvantageous, and its dustiness hinders both transport and application in the field. The change of the dusty form to pellets, as well as standardization of chemical composition by mixing the ashes from combustion of pure biomass with the ashes from co-combustion of biomass with coal, or the ashes from lignite combustion, creates new possibilities for their use in agriculture. The ashes contain many macro- and micronutrients valuable for plants, with the exception of nitrogen. Another option, when it comes to the use of fly ashes, derived from co-combustion, is their application to the hygienization of sewage sludge from municipal sewage treatment plants. Due to the high content of calcium, sodium and potassium, ashes could be used in agriculture together with sewage sludge [Rosik-Dulewska 2009, 2012, Rosik-Dulewska et al. 2008]. Additionally, ashes from biomass cocombustion can be applied in road construction [Myszkowska et al. 2011].

From an ecological point of view, the return of ash originated from the combustion of biomass 
to the soil, from which the plants designed for thermal processing were collected, is consistent with the principle of sustainable development. Considerable part of macro- and micronutrients taken up from the soil by plants returns to the habitat, closing the circulation of mineral compounds. The research has shown that by-products derived from the combustion of biomass produced in unpolluted agricultural areas do not contain toxic substances (including heavy metals) in the amount creating environmental hazard [Wacławowicz 2011].

\section{Economic aspects}

Production of plants for energy purposes is stimulated - on the one hand - by the demand from the fuel-energy sector for this kind of raw material, and - on the other hand - by subsidies for acreage of these crops. As is known from the literature, in Poland the demand for biomass exceeds its supply [Grzybek 2008]. The impact on the use of biomass in energy sector have the following factors: the dispersion of the sources of its acquisition, the diversity of its forms, as well as a variety of manufacturers and consumers of biomass and energy. Biomass can be produced in many forms e.g. sawdust and wood chips, straw, grains and pellets.

Biomass market in Poland is unstable. It requires greater financial contribution and appropriate management to attract investors. The development of the biomass market is affected by the following factors: the acreage of agricultural production land, yields of biomass, the price ratio of biomass to basic crops e.g. wheat. The trade in energy crops has specific procedures, by selling biomass to the processing units. To revive the biomass market in Poland, it is necessary to develop and implement a program of energy plant cultivation and the construction of small installations to its processing into the secondary energy carriers. It is necessary to maintain a balance in the system: capital - investor - credit [Jabłoński 2008]. Moreover, structures dealing with the organization, supervision and coordination of activities related to establishing energy crop plantations, including research plantations, as well as cooperation with units receiving and processing of biomass should be created. Currently single plantations are set up, mostly of energy willow. Manufacturers of energy crops, with no organized sales and processing, not only cease to invest in further development of the plantations, but also effectively discourage other potential biomass producers. An essential element of the future biomass market should be a program of the association of small farms in new producer's structures. This would facilitate the acquisition of structural funds for energy crop production, the conduct of soil and climate research, the creation of information soil bank, proposing a set of crops suitable for a specific area [Jabłoński 2008].

From an economic point of view, it is essential to create own, local market of biomass e.g. in the region where the power plant is located. This will reduce the cost of biomass transportation of and provide its constant flow to the recipient. The form in which the biomass is transported is also important. In the case of the described power plant located in Opole Province, the most favorable is transport of the combusted straw in the form of pellets, because its bulk density is more than three times greater, than logs, which allows for less number of trucks with pellets. In addition, the pellet market is broadly available and there is no need to organize it [Kozłowski, Cygan 2011].

The economic aspect, without which the cocombustion process could not be commenced, are investment expenditures. The power plant that intends to burn biomass must bear the cost to adapt the current installation or build a new one. Such installations also require expenditures for their maintenance due to their exploitation. Subsidies for power plants intending to burn the biomass would be helpful, since they allow the plants to reduce the costs of installations. Currently, power plants cope with this problem by balancing their budget. Their annual net income includes revenues from the sales of produced energy and byproducts e.g. furnace waste, minus cost of fuels, raw materials, services (water, sewage), operation of installation, and its maintenance, supplies and insurance. These costs are dependent on the scale of co-combustion process, and are different in small and large power plants [Mcllveen-Wright et al. 2011].

\section{Technological aspects}

Biomass co-combustion process has a lot of disadvantages. There is a risk of explosion during the combustion of biomass with coal at the following stages of the introduction of fuel [Czech 2011]:

- unloading at the storage yard,

- storage, 
- administration of biomass from storage yard on carburization routes,

- fuel transport by carburization routes,

- fuel storage in boiler reservoirs,

- fuel supplying from the reservoir through the feeder to a coal mill,

- co-milling processes in a coal mill,

- feeding of dust-air mixture into the combustion chamber.

During the administration of dry biomass to carburization routes strong dust emissions occur. This is dangerous for workers, because it can reduce visibility and cause breathing problems, as well as negatively influences nearby installations. Besides, during the transport of the mixture of biomass and hard coal secondary dust emissions occurs under transferring points, which poses a threat to the devices that are low at floor level, which are inundated with dust, negatively affecting their work. This is an example of the fault in anti-explosion protection system. In order to avoid the danger of explosion at carburization routes, it is important to adhere to the principles of occupational safety and health. The essential basic requirements of explosion protection include [Czech 2011]:

- building of the systems of fuel moistening or dedusting devices on transferring points,

- fuel temperature control during transport thermovision,

- maintaining the cleanliness of the carburization routes e.g. through the central vacuum cleaning system (there is a problem with the ejection of fine fractions of fuel accumulated in cyclones).

Significant threat to the security are also so called fuel overhangs in the fuel reservoir, leading to the formation of caverns, that allow for blowing in the direction from the mill to the reservoir, through a screw feeder and fill pipe. To prevent this, a minimum level of fuel in the reservoir should be maintained, which is a "plug" that prevents blow from the mill to the reservoir, and this level is connected to the explosion pressure of dust-air mixture. Mill work may be impaired by the deposition of biomass on the internal parts of the construction. This causes inaccurate unification of the mixture composition and frequent cleaning works, disturbing steady rhythm of the mill operation [Czech 2011]. Co-combustion can also affect the operation and condition of the power boiler, where previously only hard coal was burnt. The combustion of wood with a moisture content above $30 \%$ may damage the boiler due to tar contamination, arising during the combustion of the wet fuel. The combustion of wood in the boilers not designed and constructed for this process causes excessive emissions, due to the high content of moisture and volatile compounds [Grzybek 2010].

One of the most important defects of biomass fuel is a large variation in their parameters. This characteristic feature makes the biomass to be "a technologically difficult fuel". Energetic use of biomass is significantly impeded by the presence of alkali, chlorine and low fusibility of ash. A large amount of alkaline compounds and chlorine can cause damage to the heating appliances. Sodium and potassium react with chlorine, sulfur and silicon, depending on their content in the fuel. In the case of ash, particularly important is the ratio of alkali oxides $\left(\mathrm{CaO}, \mathrm{MgO}, \mathrm{Na}_{2} \mathrm{O}\right)$ to acidic $\left(\mathrm{SiO}_{2}, \mathrm{Al}_{2} \mathrm{O}_{3}\right)$. The more reactive the alkali contained in the fuel, the higher probability of problems associated with the ash and boiler operation, as a result of adverse events, such as agglomeration, overgrowing of deposit, slag formation, or corrosion of heating components [Faber 2008]. The most important technological problems associated with the co-combustion of biomass with fossil fuels include: slag formation in boilers, corrosion processes on the surface of the boilers, deterioration in grinding a coal-biomass mixture, and agglomeration [Kobylarz 2011].

It was proved, that the most beneficial from technological and environmental point of view is the combustion of forest biomass, because - as compared to other kinds of biomass - smaller amount of ash, sulfur and nitrogen oxides and less by-products, such as gypsum and slag is formed during timber combustion. In addition, less amount of lime and ammonia has to be used to purify the flue gas. Forest biomass allows for reduction in the cost of energy production without an intensive, negative influence on installations [Wils et al. 2012]. The combustion of forest biomass causes fewer side effects than other kinds of biomass. Sometimes, however, in the power plant co-combusting forest biomass, the reduction in the emissions of carbon, sulfur and nitrogen oxides does not occur, which is caused by incomplete burning, due to the different particle sizes of wood chips. Therefore, it is necessary to mix them thoroughly in the mill. In the case of forest biomass co-combustion, improper technological 
and appliance solutions may even result in increased emissions of harmful substances into the atmospheric air, which destroys beneficial environmental effect resulting from the nature of this kind of biomass. Incomplete burning also means economically disadvantageous fall in the efficiency of the process.

The investigations (co-combustion tests), carried out in the described power plant, did not show significant changes in the work of coal mill systems, with the exception of the increased load, as well as changes in flue gas temperature, primary and secondary steam temperature, that may result from the application of a mixture of coal and biomass. In relation to coal mill load increases, due to the lower calorific value of the biomass in comparison with hard coal, for full load of a power unit, the connection of additional coal mill was required - a total of four mill systems per one power unit. Technical inspections of coal mills, coal feeders and boiler bunkers carried out immediately after testing, confirmed their proper technical condition. There was no tendency to the formation of fuel overhangs in boiler bunkers, and the problems associated with the accumulation of biomass remains in coal mill systems. There were also no significant differences in the emissions of nitrogen oxide and sulfur dioxide and deteriorated performance of electrofilters.

\section{Social aspects}

Generally, the society positively responds to information on biomass co-combustion in power plants, believing that this contributes to the protection of the environment. In addition, some power plants called biomass energy "green energy", which is associated with RES. Positive attitude towards the co-combustion of biomass also results from the increase in the number of workplaces i.e. a fall in unemployment. Small and medium-sized enterprises, supplying the larger business operators of energy market with biomass, are created. However, export of biomass can contribute to the growth in unemployment in the country to which it is exported. On the other hand, the increase in electricity costs, associated with co-combustion of biomass, is negatively perceived by the public, since it causes burdening the budget of the individuals [Morais et al. 2011].

Obtaining biomass for energy purposes by deforestation is negatively perceived by the public and causes not only many acts of dissatisfaction, but also protests. They also concern the construction of roads, especially if valuable tree stands are cut out. Acquisition of forest biomass is often seen as wood theft from the forest and leads to a decrease in the acreage of forests, which are places for recreation and rest, as well as common, widely available wealth,. Tropical forests, called "the lungs of the Earth", are also cut out for energy purposes.

The society also negatively reacts to energy crop cultivation, which is associated with a risk to the food market, similar to the addition of $10 \%$ bio-components to conventional fuels, especially that the production of biofuels may also contribute to the increase in the prices of food and agricultural products. The opponents of the energy plant cultivation believe that agricultural land should be used for food production, especially considering the impoverishment of society and hunger in many regions of the world, and the cultivation of energy crops is contrary to the principle of biodiversity protection. In addition, they claim that Polish agriculture should first secure the necessary level of food self-sufficiency and food security, and then produce biomass for energy purposes in the areas useless for the production of food and fodder [Faber 2008]. All agricultural production, especially biomass, must meet the requirements of sustainable production, which will be continually improved.

According to the forecasts, the achievement of the objectives of policies promoting RES will reduce the area of wasteland, at unchanged area of traditional crops, increase in prices of crops by $10-20 \%$ with moderate competition for space between the production of agricultural products and biofuels, or increase in prices above $50 \%$, at strong competition between these sectors of production [Grzybek 2008].

\section{CONCLUSIONS}

1. Considering the environmental protection aspect, it is known from the literature that the co-combustion of biomass can contribute to the increase in emission of some pollutants e.g. hydrocarbons into the atmospheric air.

2. According to literature data, the most advantageous method of disposal and management of ash from the process of biomass co-combustion is its utilization in fertilization of plants intended for the biomass production. It leads 
to inclusion of ash components in the closed circulation of elements in nature.

3. The tested power plant burns two kinds of biomass: forest and agricultural. Two aspects reinforce the advisability of co-combustion of forest biomass: technological, associated with the low content of ash in this kind of biomass, and social - lack of impact on food prices. However, the co-combustion of the agricultural biomass is advantageous from an economic point of view, because of the lower moisture content in agricultural biomass compared to forest biomass, and environmental protection point of view, since it does not require felling of trees.

4. The co-combustion of biomass with hard coal in power plants is accompanied by slagging and corrosion of boilers, agglomeration process, dust emissions and explosions, posing a threat to the installation of co-combustion. These negative phenomena have not took place in the tested power plant.

5. The fact that biomass requires processing before combustion is disadvantageous, because it leads to additional financial outlays for the energy needed for this purpose.

6. Not only government subsidies and EU funds, but also law regulations, establishing the supporting system for units acquiring the energy as a result of the co-combustion of biomass have an impact on the development of the biomass market. Unfortunately, lack of such legislation in Poland at the moment does not promote the development of biomass market.

\section{REFERENCES}

1. Bartosiewicz-Burczy H. 2012. Potential and energy use of biomass in Central European countries. Power Engineering 12, 860-866 (in Polish).

2. Czech J. 2011. Explosive hazards at co-combustion of biomass and hard coal - the conclusions from the inspections carried out by the National Labour Inspection in the years 2010-2011. Forum of technologies in power engineering - biomass combustion, Bełchatów (in Polish).

3. Faber A. 2008. Threats to the environment and the food market, which can cause the cultivation of energy crops. The role of biomass in energy production, Federation of Scientific and Technical Associations NOT, Polish Scientific and Technical Committee for Energy Management, Warsaw (in Polish).
4. Frączkowski P. 2011. Production of energy from biomass in Polish Energy Group PGE. Mining and Conventional Power Engineering S.A., Forum of technologies in power engineering - biomass combustion, Bełchatów (in Polish).

5. Grzybek A. 2010. Modeling of energetic use of biomass. Publishing of Technological-Nature Institute in Falenty (in Polish).

6. Grzybek A. 2008. The demand for biomass and the strategy of its energy use. The role of biomass in energy production, Federation of Scientific-Technical Associations NOT. Polish Scientific-Technical Committee for Energy Management, Warsaw (in Polish).

7. Jabłoński R. 2008. The market of biomass against current possibilities of energy plant production. Biomass in energy management in Poland. Federation of Scientific and Technical Associations NOT, Polish Scientific and Technical Committee for Energy Management, Warsaw (in Polish).

8. Juliszewski T. 2009. Heating with biomass. PWRIL Publishing, Poznań (in Polish).

9. Karpińska M., Dul Ł. 2014. Directions of energy policy in Poland and European Union in the years 2007-2030. Power Engineering 3, 149-154 (in Polish).

10. Kobylarz M. 2011. Solutions of combustion and co-combustion installations - technologies and operational safety. Forum of technologies in power engineering - biomass combustion, Bełchatów (in Polish).

11. Kozłowski W., Cygan K. 2011. The co-combustion of straw with hard coal in the big power boiler. Forum of technologies in power engineering - biomass combustion, Bełchatów (in Polish).

12. McIlveen-Wright D.R., Huang Y., Rezvani S., Mondol J.D., Redapath D., Anderson M., Hewitt N.J. 2011. Techno-economic assessment of the reduction of carbon dioxide emissions through the use of biomass co-combustion, Fuel vol. 90, 11-18.

13. Morais J., Barbosa R., Lapa N., Mendes B., Gulyurtlu I. 2011. Environmental and socio - economic assessment of co-combustion of coal, biomass and non-hazardous wastes in a Power Plant. Resources Conservation and Recycling, 55(11), 1109-1118.

14. Munir S., Nimmo W., Gibbs B.M. 2011. The effect of air staged, co-combustion of pulverized coal and biomass blends on NOx emissions and combustion efficiency. Fuel, vol. 90, 126-135.

15. Myszkowska A., Świderska-Ostapiak M., Szczygielski T. 2011. The evaluation and guidelines of the application of ashes from co-combustion in construction and agriculture. Forum of technologies in power engineering - biomass combustion, Bełchatów (in Polish). 
16. Rosik-Dulewska C. 2012. Basics of waste management, updated edition. PWN Scientific publishing, Warsaw, pp. 378 (in Polish).

17. Rosik-Dulewska C. 2009. Current state of waste management in Poland and prespectives of changes. In: J. Ozonek, M. Pawłowska (Eds) Monographs of Environmental Engineering Committee of Polish Academy of Sciences PAN 58(3), 1-10 (in Polish).

18. Rosik-Dulewska C., Karwaczyńska U., Ciesielczuk T. 2008. Leaching of PAHs from fly ash-sludge blends. Archives of Environmental Protection 34 (3), 41-47.

19. The Regulation of the Minister of Enviromnent of 4 November 2014 on emission standards for some kinds of installations, fuel combustion sources and devices of combustion or co-combustion of waste, Journal of Laws of 7 November 2014, item 1546.

20. Skrobacka H. 2007. Biomass for electric power engineering and heat engineering: opportunities and problems. "Village of Tomorrow" Publishing, Warsaw (in Polish).

21. Szymanowicz R. 2012. Physicochemical properties of fuels coming from renewable resources. Power Engineering 5, 230-235 (in Polish).
22. Świstak C. 2008. Possibilities of biomass acquisition from forest management for energy targets on the example of the Regional Directorate for National Forests in Białystok - current state and perspective 2020. The role of biomass in energy production. Federation of Scientific and Technical Associations NOT, Polish Scientific and Technical Committee for Energy Management, Warsaw (in Polish).

23. Wacławowicz R. 2011. Agricultural use of ashes from biomass combusion. Forum of technologies in power engineering - biomass combustion, Bełchatów (in Polish).

24. Wielgosinski G. 2009. Is biomass green fuel? In: J. Ozonek and M. Pawłowska (Ed.) Monographs of the Environmental Engineering Committee of the Polish Academy of Sciences PAN 58(1), 347-356.

25. Wils A., Calmano W., Dettmann P., Kaltschmitt M., Ecke H. 2012. Reduction of fuel side costs due to biomass co-combustion. J. Hazard. Mater. 207208, 147-151.

26. Wiśniewski W. 2011. The combustion of $100 \%$ of biomass - designing experience, in-service experience, applications. The forum for technologies in power engineering - biomass combustion, Bełchatów (in Polish). 